\title{
Variation in the Virulence of Strains of Mycoplasma pulmonis Related to Susceptibility to Killing by Macrophages in vivo
}

\author{
By C. J. HOWARD AND GERALDINE TAYLOR \\ Agricultural Research Council Institute for Research on Animal Diseases, \\ Compton, Newbury, Berkshire, RG16 0NN
}

(Received 31 January 1979)

\begin{abstract}
The virulence of five strains of Mycoplasma pulmonis, as judged by their ability to survive in the respiratory tract and induce pneumonia in CBA mice, was related to the ability of viable organisms to persist in the peritoneal cavity. This appeared to be the result of differences in the ability of the strains to resist killing by peritoneal macrophages in vivo. It is suggested that resistance to phagocytosis by macrophages is an important determinant of virulence for $M$. pulmonis.
\end{abstract}

\section{INTRODUCTION}

Many mycoplasma species are pathogenic but there are differences in the virulence of various strains within a species, e.g. Mycoplasma mycoides subsp. mycoides, M. dispar and ureaplasmas in cattle (Whittlestone, 1972; Howard et al., 1973; Brownlie et al., 1976) and M. pneumoniae in hamsters (Dajani et al., 1965; Lipman \& Clyde, 1969). It is generally agreed that virulence determinants are complex and a variety of factors are involved. Various properties of the mycoplasmas have been examined in an attempt to explain variations in virulence including production of toxins and ability to attach to cells (Lipman \& Clyde, 1969; Lipman et al., 1969; Whittlestone, 1972). However, these properties alone do not provide a simple in vitro measure of virulence. Toxins, such as haemolysins, are produced by avirulent strains or non-pathogenic species. Similarly, although attachment may be a necessary first step in the production of disease, non-pathogenic species such as Acholeplasma laidlawii are able to attach to cells, as are avirulent strains of $M$. pneumoniae (Razin, 1978).

The predominant phagocytic cell in the non-inflamed respiratory tract is the macrophage (Green \& Kass, 1964) and differences in susceptibility to phagocytosis have been related to strain virulence for a number of bacterial species (Glynn, 1972; Smith, 1978). Mycoplasma pulmonis is a cause of naturally occurring pneumonia in mice. Pneumonia can be induced by the intranasal inoculation of mice with this mycoplasma (Tully, 1969; Cassell et al., 1973) and, as with other mycoplasma species, strains of $M$. pulmonis vary considerably in their virulence (Taylor, 1975). It is therefore possible that variation in the virulence of strains of $M$. pulmonis might be due to differences in their interactions with alveolar macrophages. Mycoplasmas have been seen in phagocytes from the lungs of infected animals (Organick et al., 1966; Whittlestone, 1972; Cassell et al., 1973), although it has been reported that in the absence of specific antibody mycoplasmas persist and grow in macrophage cultures in vitro (Jones \& Hirsch, 1971; Cole \& Ward, 1973; Powell \& Clyde, 1975; Howard et al., 1976).

This study was undertaken to determine whether differences in the virulence of various strains of $M$. pulmonis could be explained by their susceptibility to killing by macrophages. 
Initially, strains of different virulence were compared in several phagocytosis systems in vitro. Subsequently, an alternative method was employed. Variation in the ability of virulent and avirulent strains of Salmonella typhimurium to survive in the peritoneal cavity of mice has been reported to be due to variation in their susceptibility to killing by peritoneal macrophages (Whitby \& Rowley, 1959; Rowley \& Whitby, 1959). In contrast to the respiratory tract, the peritoneal cavity has the advantage, for experimental studies, that any decrease in the number of viable organisms will not be due to their removal from the site of inoculation by ciliary activity and neither should an inability to attach to respiratory epithelium affect ability to persist at this site. The abilities of $M$. pulmonis strains of different virulence to survive in the peritoneal cavity of mice were therefore compared and evidence was sought to show that the disappearance of viable organisms from the peritoneal cavity was due to killing by macrophages.

\section{METHODS}

Mycoplasma strains. The five strains of M.pulmonis used in this study are listed in Table 1. Strain JB was the same as that described previously (Taylor et al., 1977). Strain Negroni was obtained from R. H. Leach, Mycoplasma Reference Laboratory, Norwich. Strains 80, 66 and Ash (PG 34) were obtained from A. Hill, Laboratory Animal Centre, Carshalton.

Culture media. Liquid and solid media used for growing the strains and for viable counts were as described by Taylor et al. (1977). Small volumes of broth cultures were stored at $-70^{\circ} \mathrm{C}$ to provide standard inocula.

In vitro phagocytosis methods. Three in vitro systems were used. (i) Macrophages were obtained from mice by peritoneal lavage (Stuart, 1967) and maintained as monolayers in plastic Petri dishes (30 mm diam.) with Medium 199 (Wellcome Laboratories, Beckenham) containing $0 \cdot 11 \%(\mathrm{w} / \mathrm{v}) \mathrm{NaHCO}_{3}, 0 \cdot 1 \%(\mathrm{w} / \mathrm{v})$ ampicillin (Beechams, Crawley), 25 units mycostatin $\mathrm{ml}^{-1}$ (Squibb, London) and $10 \%$ (v/v) heated $\left(56{ }^{\circ} \mathrm{C}, 30 \mathrm{~min}\right)$ foetal calf serum. After $24 \mathrm{~h}$ incubation at $37^{\circ} \mathrm{C}$, these cell cultures were infected with $M$. pulmonis strain $\mathrm{JB}, 80$, Negroni or Ash and the survival of the strains was compared over a $48 \mathrm{~h}$ incubation period at $37^{\circ} \mathrm{C}$. The mycoplasma and macrophage concentrations were as described previously (Howard et al., 1976).

(ii) Normal macrophages were obtained in a manner similar to that described above from groups of 20 mice by washing out the peritoneal cavity with $4 \mathrm{ml}$ maintenance medium. This provided a suspension of $10^{4 \cdot 8}$ cells $\mathrm{ml}^{-1}$ of which $<1 \%$ stained with $0.1 \%$ trypan blue. Mycoplasma pulmonis strains JB or Negroni were added to the macrophages in suspension, immediately after their collection rather than after $24 \mathrm{~h}$ culture in vitro, to give a mycoplasma/cell ratio of $2: 1$, and $2 \mathrm{ml}$ portions were dispensed into $30 \mathrm{~mm}$ diam. plastic Petri dishes. The number of colony-forming units (c.f.u.) of $M$. pulmonis present at time zero and after 1,2 and $4 \mathrm{~h}$ incubation at $37^{\circ} \mathrm{C}$ in $5 \%(\mathrm{v} / \mathrm{v}) \mathrm{CO}_{2}$ in air was determined on triplicate samples.

(iii) Strains JB or Negroni were added to suspensions of peritoneal macrophages, obtained as above but concentrated by centrifuging at $90 \mathrm{~g}$ for $5 \mathrm{~min}$ at $4{ }^{\circ} \mathrm{C}$ to give $10^{6 \cdot 8}$ cells $\mathrm{ml}^{-1}$ in maintenance medium containing 10 units heparin $\mathrm{ml}^{-1}$ (Evans Medical, Liverpool). This suspension, which had a mycoplasma/cell ratio of $1: 1$, was dispensed in $2 \mathrm{ml}$ portions in silicone-treated $5 \mathrm{ml}$ glass bottles. Samples from triplicate bottles were titrated at time zero and after 1,2 and $4 \mathrm{~h}$ rolling $\left(60 \mathrm{rev} . \mathrm{min}^{-1}\right)$ at $37^{\circ} \mathrm{C}$.

Inoculation and sampling of mice. Male CBA mice of specific pathogen-free status were bred at this Institute (Howard et al., 1978). To compare the pathogenicity of the five $M$. pulmonis strains for these mice, anaesthetized animals were inoculated intranasally with $50 \mu \mathrm{l}$ of a suspension of $M$. pulmonis, containing $10^{5 \cdot 4}$ c.f.u. in phosphate-buffered saline (PBS) (Taylor et al., 1977). Control mice were inoculated with PBS. At 8 and $15 \mathrm{~d}$ after inoculation, five mice from each group were killed by intraperitoneal inoculation with $0.2 \mathrm{ml}$ Sagatal (May \& Baker, Dagenham) and lung washings were obtained. The numbers of mycoplasmas and leucocytes present in lung wash fluid were determined and the lungs were fixed in formalin for histopathological examination. Severity of lung lesions was determined as described previously and expressed as a lesion score (Howard et al., 1978).

In order to determine the rates of clearance of $M$. pulmonis from the peritoneal cavity, mice were inoculated intraperitoneally with $10^{6 \cdot 1}$ c.f.u. of the various mycoplasma strains suspended in $250 \mu 1$ PBS. Immediately after inoculation five mice were killed by intraperitoneal inoculation with $0 \cdot 2 \mathrm{ml} \mathrm{Sagatal}$ and the peritoneal cavity was washed out with $4 \mathrm{ml}$ PBS containing 10 units heparin $\mathrm{ml}^{-1}$. Further groups of five mice were killed 1, 2 and $4 \mathrm{~h}$ after intraperitoneal inoculation of mycoplasmas and the number of mycoplasmas $\mathrm{ml}^{-1}$ in peritoneal washings was determined. No obvious effect of Sagatal on the viability of mycoplasmas was noted.

The effect of silica on the rate of disappearance of viable organisms from the peritoneal cavity was determined by inoculating mice with $20,10,5,2$ or $1 \mathrm{mg}$ silica (Aerosil; Bush Beach \& Segner Bayley, 
Table 1. Comparative pathogenicity of five strains of $M$. pulmonis for CBA mice examined 8 and $15 d$ after intranasal inoculation

Mice were inoculated with suspensions of $M$. pulmonis containing $10^{5 \cdot 4} \mathrm{c}$.f.u.

\begin{tabular}{|c|c|c|c|c|c|c|}
\hline \multirow[b]{2}{*}{ M. pulmonis strain } & \multicolumn{2}{|c|}{$\begin{array}{l}\text { No. of mycoplasmas ml-1 } \\
\text { in lung wash* }\left(10^{n}\right)\end{array}$} & \multicolumn{2}{|c|}{ Lesion score* } & \multicolumn{2}{|c|}{$\begin{array}{l}\text { No. of leucocytes ml-1 } \\
\text { in lung wash* }\left(10^{n}\right)\end{array}$} \\
\hline & Day 8 & Day 15 & Day 8 & Day 15 & Day 8 & Day 15 \\
\hline $\begin{array}{l}\text { JB } \\
80 \\
66 \\
\text { Negroni } \\
\text { Ash } \\
\text { Control }\end{array}$ & $\begin{array}{r}6.9 \\
6.2 \\
4.9 \\
<1.0 \\
<1.0 \\
<1.0\end{array}$ & $\begin{array}{r}7.2 \\
6.0 \\
5.1 \\
<1.0 \\
<1.0 \\
<1.0\end{array}$ & $\begin{array}{l}1 \cdot 4 \\
1 \cdot 1 \\
0 \cdot 8 \\
0 \cdot 1 \\
0 \\
0 \cdot 1\end{array}$ & $\begin{array}{l}2 \cdot 5 \\
0 \cdot 8 \\
0 \cdot 8 \\
0 \\
0 \\
0\end{array}$ & $\begin{array}{l}7 \cdot 2 \\
6 \cdot 1 \\
5 \cdot 9 \\
4 \cdot 5 \\
4 \cdot 5 \\
4 \cdot 2\end{array}$ & $\begin{array}{l}7 \cdot 2 \\
6 \cdot 0 \\
5 \cdot 7 \\
4 \cdot 3 \\
4 \cdot 6 \\
4 \cdot 6\end{array}$ \\
\hline Standard error $\dagger$ & $0 \cdot 36$ & 0.44 & $0 \cdot 22$ & 0.30 & 0.32 & $0 \cdot 36$ \\
\hline
\end{tabular}

* Mean of groups of five mice.

$\dagger$ Average standard error for comparisons between means in columns, by analysis of variance.

London) suspended in $0.5 \mathrm{ml}$ PBS $2 \mathrm{~h}$ before they were inoculated intraperitoneally with mycoplasmas. Control mice were inoculated with PBS.

Labelling mycoplasmas with ${ }^{51} \mathrm{Cr}$. The organisms from an overnight broth culture $(40 \mathrm{ml})$ of strain Negroni were harvested by centrifugation at $8000 \mathrm{~g}$, washed twice with PBS and resuspended in $250 \mu 1$ PBS. The mycoplasma suspension was mixed with $500 \mu \mathrm{l}$ of sodium $\left[{ }^{51} \mathrm{Cr}\right]$ chromate $(0.5 \mathrm{mCi})$ and incubated for $1 \mathrm{~h}$ at $37^{\circ} \mathrm{C}$. The mycoplasmas were then washed four times with PBS by centrifugation and resuspended in $4.5 \mathrm{ml}$ PBS. The final suspension contained $2 \times 10^{6}$ c.f.u. $\mathrm{ml}^{-1}$ and $2.3 \times 10^{5} \mathrm{c}$.p.m. ml-1. Samples containing ${ }^{51} \mathrm{Cr}$ were counted using a $\gamma$ counter (Nuclear Enterprises, Edinburgh).

Statistical analysis. Where results were analysed statistically a standard analysis of variance (one way classification) was used.

\section{RESULTS}

Comparative pathogenicity of five strains of $M$. pulmonis for $C B A$ mice. The numbers of mycoplasmas and leucocytes present in lung washings and the extent of pneumonia (lesion score) observed 8 and $15 \mathrm{~d}$ after intranasal inoculation of mice with $10^{5 \cdot 4} \mathrm{c.f} . \mathrm{u}$. of five M. pulmonis strains are recorded in Table 1 .

Strains Ash and Negroni did not survive in the lung and did not induce any disease as judged by the number of leucocytes in lung washings and the histopathological lesions, neither of which were significantly different from control values.

The lung lesions induced by strains JB, 80 and 66 consisted of peribronchiolar and perivascular accumulations of lymphoid cells accompanied by infiltration of the parenchyma with polymorphonuclear leucocytes and macrophages. The relative contribution of these two features to the lesions did not appear different in mice inoculated with strains $J B$, 80 or 66 . However, the peribronchiolar and perivascular accumulations of cells induced by these strains were more pronounced at $15 \mathrm{~d}$ than at $8 \mathrm{~d}$. Very similar results were obtained when the experiment was repeated.

Thus, if the numbers of c.f.u. and leucocytes in lung washings and lesion scores are taken into account, three of the five $M$. pulmonis strains were virulent for CBA mice and these were, in decreasing order of virulence, JB, 80 and 66. Strains Ash and Negroni were avirulent.

In vitro phagocytosis experiments. None of the in vitro phagocytosis systems used showed any obvious differences in the ability of the virulent $M$. pulmonis strains, JB and 80 , or the avirulent strains, Ash and Negroni, to survive in the presence of cultured murine macrophages.

Survival of $M$. pulmonis strains in the peritoneal cavity. There was a marked variation in the ability of the five strains to survive in the peritoneal cavity (Fig. 1). Strains Negroni and 


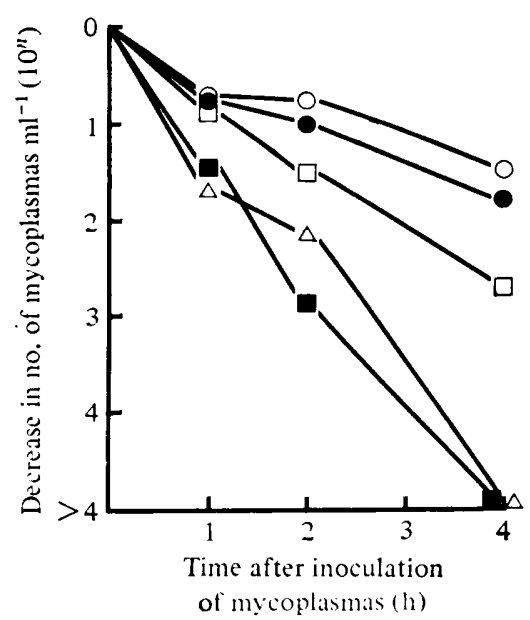

Fig. 1

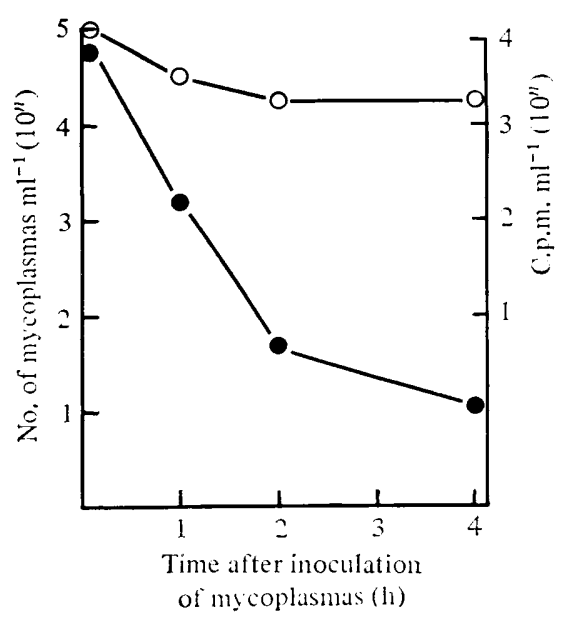

Fig. 2

Fig. 1. Comparative survival of five $M$. pulmonis strains in the peritoneal cavity of CBA mice. Each point represents the mean number of c.f.u. $\mathrm{ml}^{-1}$ in peritoneal washings from groups of five mice inoculated with $10^{6 \cdot 1}$ c.f.u. of strains JB $(\bigcirc), 80(\bullet), 66(\square)$, Ash $(\triangle)$ or Negroni $(\square)$.

Fig. 2. Clearance of ${ }^{51} \mathrm{Cr}$-labelled $M$. pulmonis strain Negroni from the peritoneal cavity of mice. Each point represents the mean number of c.f.u. $\mathrm{ml}^{-1}(\Theta)$ or c.p.m. $\mathrm{ml}^{-1}(\bigcirc)$ in peritoneal washings from groups of five mice.

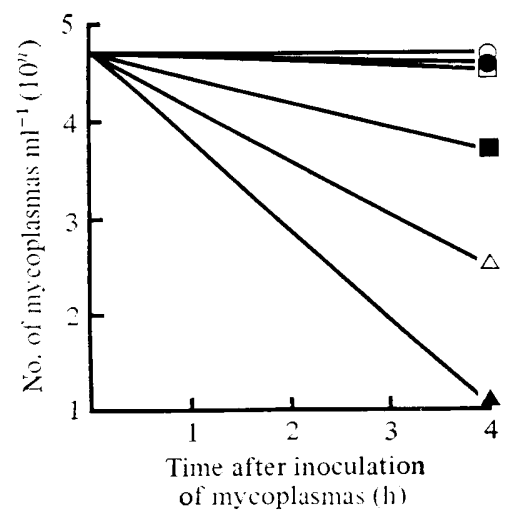

Fig. 3. Effect of silica on the disappearance of $M$. pulmonis strain Negroni from the peritoneal cavity of mice. Each point represents the mean number of c.f.u. $\mathrm{ml}^{-1}$ in peritoneal washings from groups of five mice inoculated intraperitoneally with $0(\Delta), 1(\triangle), 2(\square), 5(O), 10(\square)$ or $20(\bigcirc) \mathrm{mg}$ silica $2 \mathrm{~h}$ before inoculation of mycoplasmas.

Ash were not recovered from the peritoneal cavity $4 \mathrm{~h}$ after intraperitoneal inoculation, whereas all three virulent strains could be recovered from peritoneal washings at this time. Of the three virulent strains, JB survived best, strain 80 slightly less well and strain 66 least well. Thus the disappearance of viable mycoplasmas from the peritoneal cavity correlated with the virulence for the respiratory tract.

Survival of ${ }^{51} \mathrm{Cr}$-labelled $\mathrm{M}$. pulmonis strain Negroni in the peritoneal cavity of mice. The rate of disappearance of viable organisms, following the intraperitoneal inoculation of ${ }^{51} \mathrm{Cr}$-labelled $M$. pulmonis, was more rapid than the rate of disappearance of radioactivity from the peritoneum (Fig. 2).

Effect of silica on the rate of killing of $M$. pulmonis in the peritoneal cavity. The rate of disappearance of viable $M$. pulmonis strain Negroni from the peritoneal cavity was markedly 
reduced in mice that had been treated $2 \mathrm{~h}$ previously with silica inoculated intraperitoneally when compared with the rate of disappearance in control mice (Fig. 3). The effect of silica was dose-related.

\section{DISCUSSION}

The virulence of the five strains of $M$. pulmonis was measured by comparing their ability to infect and induce pneumonia in CBA mice. For each strain the rate at which the number of viable organisms decreased in the peritoneal cavity was inversely related to virulence for the respiratory tract. The disappearance of viable micro-organisms from the peritoneal cavity is considered to be due to killing by the peritoneal macrophages (Whitby \& Rowley, 1959; Rowley \& Whitby, 1959). Furthermore, the decrease in viable count observed in the peritoneal cavity proceeded at a faster rate than the disappearance of radioactive label indicating that the decrease in the number of viable organisms was not due merely to removal of mycoplasmas from this site but to killing in situ. Silica is considered to be toxic for macrophages (Allison et al., 1966; Kessel et al., 1963; Zisman et al., 1970). Thus, the observation that treatment with silica inhibited the killing of mycoplasmas supports the view that the mycoplasmas are killed in the peritoneal cavity by these cells.

In contrast to the observations in vivo, no differences were detected between the virulent and avirulent strains in their survival in macrophage cultures. It has been noted on several occasions with different mycoplasma species and cells from various animal species that mycoplasmas can survive in vitro in cultures of phagocytic cells, provided specific antibody has not been added to the system (Jones \& Hirsch, 1971; Cole \& Ward, 1973; Powell \& Clyde, 1975; Howard et al., 1976). However, experiments in vivo support the view that ability to resist killing by normal macrophages is an important virulence factor of M.pulmonis. Possible explanations of why the experiments in vitro did not demonstrate differences between strains may be that macrophages function more efficiently in their normal environment and/or an opsonin may be absent in the in vitro system.

Other reports suggest that mycoplasma virulence could be related to susceptibility to killing by macrophages. Cole \& Ward (1973) found slight differences between the survival of strains of $M$. arthritidis of varying virulence in rodent macrophage cultures. Also, Smith (1968) reported that the virulence of $M$. mycoides subsp. mycoides for cattle was related to the ability of the strains to cause a bacteraemia in mice following intraperitoneal inoculation.

A variety of mechanisms may be responsible for variations in susceptibility to phagocytosis. Resistance of mycoplasmas to macrophage killing in vivo might be due to a passive mechanism such as the possession of surface antigens which inhibit opsonization and phagocytosis as seen with certain bacteria (Glynn, 1972; Smith, 1978). Jones et al. (1972) reported that $M$. pulmonis was more readily phagocytosed as a result of trypsin treatment and suggested that this might be due to the loss of some surface component which inhibited phagocytosis. Alternatively, strain variation may be due to an active mechanism whereby the mycoplasmas exert an inhibitory effect on phagocytosis. Evidence supporting this possibility comes from the report of Simberkoff \& Elsbach (1971) that the phagocytosis of Escherichia coli was inhibited by previous exposure of neutrophils to $M$. hominis.

Although it is possible that alveolar and peritoneal macrophages behave differently, the results presented here imply that resistance to phagocytosis by normal macrophages is an important virulence determinant of $M$. pulmonis. This may also be true for other mycoplasma species. Thus, the ability of mycoplasmas to avoid phagocytosis may be added to the list of virulence factors for these organisms.

We thank Mr A. Patterson for help and advice with the statistical analysis and Miss J. Holdsworth and Mrs M. Martin for their able assistance in sampling mice. 


\section{REFERENCES}

Allison, A. C., Harington, J. S. \& Birbeck, M. (1966). An examination of the cytotoxic effects of silica on macrophages. Journal of Experimental Medicine 124, 141-154.

Brownlie, J., Howard, C. J. \& Gourlay, R. N. (1976). Pathogenicity of certain mycoplasma species in the bovine mammary gland. Research in Veterinary Science 20, 261-266.

Cassell, G. H., Lindsey, J. R., Overcash, R. G. \& BAKER, H. J. (1973). Murine mycoplasma respiratory disease. Annals of the New York Academy of Sciences 225, 395-412.

COLE, B. C. \& WARD, J. R. (1973). Interaction of Mycoplasma arthritidis and other mycoplasmas with murine peritoneal macrophages. Infection and Immunity 7, 691-699.

Dajani, A. S., Clyde, W. A. \& Denny, F. W. (1965). Experimental infection with Mycoplasma pneumoniae (Eaton's agent). Journal of Experimental Medicine 121, 1071-1086.

GlynN, A. A. (1972). Bacterial factors inhibiting host defence mechanisms. Symposia of the Society for General Microbiology 22, 75-112.

Green, G. M. \& Kass, E. H. (1964). The role of the alveolar macrophage in the clearance of bacteria from the lung. Journal of Experimental Medicine 119, 167-176.

Howard, C. J., Gourlay, R. N. \& Brownlie, J. (1973). The virulence of $T$-mycoplasmas, isolated from various animal species, assayed by intramammary inoculation in cattle. Journal of Hygiene 71, 163-170.

Howard, C. J., Taylor, G. Collins, J. \& Gourlay, R. N. (1976). Interaction of Mycoplasma dispar and Mycoplasma agalactiae subsp. bovis with bovine alveolar macrophages and bovine lacteal polymorphonuclear leucocytes. Infection and Immunity 14, 11-17.

Howard, C. J., Stott, E. J. \& Taylor, G. (1978). The effect of pneumonia induced in mice with Mycoplasma pulmonis on resistance to subsequent bacterial infection and the effect of a respiratory infection with Sendai virus on the resistance of mice to Mycoplasma pulmonis. Journal of General Microbiology 109, 79-87.

JoNES, T. C. \& HrRSCH, J. G. (1971). The interaction in vitro of Mycoplasma pulmonis with mouse peritoneal macrophages and L-cells. Journal of Experimental Medicine 133, 231-259.

Jones, T. C., YeH, S. \& HiRSCH, J. G. (1972). Studies on attachment and ingestion phases of phagocytosis of Mycoplasma pulmonis by mouse peritoneal macrophages. Proceedings of the Society for Experimental Biology and Medicine 139, 464-470.

Kessel, R. W. I., Monaco, L. \& Marchiso, M. A. (1963). The specificity of the cytotoxic action of silica - a study in vitro. British Journal of Experimental Pathology 44, 351-364.

Lipman, R. P. \& Clyde, W. A. (1969). The interrelationship of virulence, cytadsorption, and peroxide formation in Mycoplasma pneumoniae.
Proceedings of the Society for Experimental Biology and Medicine 131, 1163-1167.

lipman, R. P., Clyde, W. A. \& Denny, F. W. (1969). Characteristics of virulent, attenuated and avirulent Mycoplasma pneumoniae strains. Journal of Bacteriology 100, 1037-1043.

Organick, A. B., Sifgesmund, K. A. \& Lutsky, I. I. (1966). Pneumonia due to mycoplasma in gnotobiotic mice. II. Localisation of Mycoplasma pulmonis in the lungs of infected gnotobiotic mice by electron microscopy. Journal of Bacteriology 92, 1164-1176.

Powell, D. A. \& Clyde, W. A. (1975). Opsonin reversible resistance of Mycoplasma pneumoniae to in vitro phagocytosis by alveolar macrophages. Infection and Immunity 11, 540-550.

RAZIN, S. (1978). The mycoplasmas. Microbiological Reviews 42, 414-470.

Rowley, D. \& Whitby, J. L. (1959). The bactericidal activity of mouse macrophages in vitro. British Journal of Experimental Pathology 40, 507-515.

Simberkoff, M. S. \& Elsbach, P. (1971). The interaction in vitro between polymorphonuclear leucocytes and mycoplasma. Journal of Experimental Medicine 134, 1417-1430.

Sмттн, G. R. (1968). Factors affecting bacteriaemia in mice inoculated with Mycoplasma mycoides var. mycoides. Journal of Comparative Pathology 78, 267-274.

SMITH, H. (1978). Microbial surfaces in relation to pathogenicity. Bacteriological Reviews 41, 475500.

STUART, A. E. (1967). Techniques for the study of phagocytes. In Handbook of Experimental Immunology, pp. 1034-1053. Edited by D. M. Weir. Oxford \& Edinburgh: Blackwell Scientific Publications.

TAYLOR, G. (1975). Studies on immune mechanisms in Mycoplasma infections. Ph.D. thesis, University of London.

TAYlor, G., Howard, C. J. \& Gourlay, R. N. (1977). Protective effect of vaccines on Mycoplasma pulmonis induced respiratory disease of mice. Infection and Immunity 16, 422-431.

TulLy, J. G. (1969). Murine mycoplasmas. In The Mycoplasmatales and L-phase of Bacteria, pp. 571 605. Edited by L. Hayflick. Amsterdam: NorthHolland Publishing Co.

WhitBy, J. L. \& Rowley, D. (1959). The role of macrophages in the elimination of bacteria from the mouse peritoneum. British Journal of Experimental Pathology 40, 358-370.

Whittlestone, P. (1972). Pathogenicity of mycoplasmas in animals. Symposia of the Society for General Microbiology 22, 217-250.

Zisman, B., Hirsch, M. S. \& Allison, A. C. (1970). Selective effects of anti-macrophage serum, silica and anti-lymphocyte serum on pathogenesis of Herpesvirus infection of young adult mice. Journal of Immunology 104, 1155-1159. 